\title{
D-limonene exhibits anti-inflammatory and antioxidant properties in an ulcerative colitis rat model via regulation of iNOS, COX-2, PGE2 and ERK signaling pathways
}

\author{
LIHUA YU $^{1}$, JING YAN ${ }^{2}$ and ZHIGUANG SUN ${ }^{2}$ \\ ${ }^{1}$ Department of Gastroenterology, Wuxi Third People's Hospital Affiliated to Nanjing \\ University of Chinese Medicine, Wuxi, Jiangsu $214041{ }^{2}$ The First Clinical Medical College, \\ Nanjing University of Chinese Medicine, Nanjing, Jiangsu 210023, P.R. China
}

Received December 7, 2015; Accepted December 9, 2016

DOI: $10.3892 / \mathrm{mmr} .2017 .6241$

\begin{abstract}
D-limonene has been demonstrated to have important immunomodulatory properties, including antitumor effects, and may alleviate asthma and allergies. In the present study, the anti-inflammatory effects of D-limonene were investigated in an ulcerative colitis (UC) rat model. Healthy male Sprague-Dawley rats were randomly divided into control, untreated UC, and treatment with 50 or $100 \mathrm{mg} / \mathrm{kg}$ D-limonene UC groups. In UC rats, disease activity and colonic mucosa damage were significantly reduced by the anti-inflammatory effects of D-limonene, via suppression of matrix metalloproteinase (MMP)-2 and -9 gene expression. In addition, treatment with D-limonene significantly increased antioxidant, inducible nitric oxide synthase (iNOS) and cyclooxygenase-2 (COX-2) protein expression levels in UC rats. A decrease in prostaglandin E2 (PGE2) production, transforming growth factor- $\beta$ (TGF- $\beta$ ) gene expression and an increase phosphorylated-extracellular signal regulated kinase (ERK) 1/2 expression levelswere observed in UC rats treated with D-limonene. In conclusion, D-limonene reduced MMP-2 and -9 mRNA expression levels via regulation of the iNOS, COX-2, PGE2, TGF- $\beta$ and ERK1/2 signaling pathways in a UC rat model, indicating its potential antioxidant and anti-inflammatory properties.
\end{abstract}

\section{Introduction}

Ulcerative colitis (UC) is a non-specific type of inflammation with an unknown cause. Lesions exhibit continuous and

Correspondence to: Professor Zhiguang Sun, The First Clinical Medical College, Nanjing University of Chinese Medicine, 138 Xianlin Avenue, Xianlin University Town, Nanjing, Jiangsu 210023, P.R. China

E-mail: zhiguangsun163@163.com

Key words: D-limonene, ulcerative colitis, inflammatory, antioxidant diffuse distribution, primarily in the rectum and sigmoid colon of the large intestine (1). Typical clinical symptoms of UC include abdominal pain and diarrhea (2). As a systemic disease, it may lead to further manifestations in certain patients, including enteropathic arthritis, bowel disease, hepatobiliary diseases including primary sclerosing cholangitis, and eye and skin damage (3). UC has a worldwide incidence of 0.5-24.5 cases per 100,000. Notably, the incidence of UC is lowest in developing countries, and highest in North America and Western Europe (4). At present, the incidence of UC in Central Europe and Eastern Europe is increasing; however, it is steadily decreasing in Western Europe and Scandinavia (5). UC was first identified in 1859 , yet its etiology remains unclear. A recent study on the underlying molecular mechanisms of the disease has furthered the understanding of the etiology of $\mathrm{UC}(6)$.

UC has numerous similarities with infectious enteritis and can cause microbial inflammation of the intestinal tract (7). However, no microorganism has yet been identified to be associated with UC. There may not be a single cause of the disease, as there is no evidence of infection in patients with UC. In countries with high incidences of UC the incidence of bowel infection is low and in developing countries with poor sanitation, the consumption of unprocessed food is a protective factor (8). The frequent use of antibiotics in childhood leads to an increased risk of UC, and antimicrobial agents are ineffective in the treatment of UC (9). Cultivation of feces from patients with UC has provided inconsistent results. Increasing evidence has indicated that there is an abnormal mucosal immune response between intestinal bacteria and the mucous membrane in patients with UC (10). Molecular biology techniques have revealed that the adult intestinal space may accommodate $>50$ types of bacteria, that strains gradually increase in number along the small intestine and that Gram-negative bacteria predominate (11). There are up to $\sim 10^{12}$ bacteria per $\mathrm{cm}$ in the large intestine. Currently, $>50 \%$ of strains cannot be cultured by humans (12). D-limonene (Fig. 1) is a monoterpenoid, present in citrus and numerous other plants (13). It has been demonstrated that D-limonene may have broad anticancer properties. A previous study (14) revealed that D-limonene has significant inhibitory effects in 
animal models of breast, liver, lung, stomach and skin cancers, without clear adverse reactions. In addition, D-limonene may inhibit gastrointestinal reflux, promote healthy motility of the intestines, dissolve gallstones, relieve angina and prevent bacterial infection $(15,16)$. The present study aimed to investigate the potential anti-inflammatory and antioxidant effects of D-limonene in a UC rat model, and the underlying mechanisms.

\section{Materials and methods}

Materials. 2,4,6-trinitrobenzenesulfonic acid solution and D-limonene were obtained from Sigma-Aldrich; Merck KGaA (Darmstadt, Germany). Tumor necrosis factor- $\alpha$ (TNF- $\alpha$; R019), interleukin (IL)-1 $\beta$ (H002), IL-6, nuclear factor- $\kappa \mathrm{B}$ (NF-кB; H202), superoxide dismutase (SOD; A001-3), glutathione (GSH; A006-2) and prostaglandin (PG) E2ELISA kits were obtained from the Nanjing Jiancheng Bioengineering Institute (Jiangsu, China). A bicinchoninic acid (BCA) assay kit was obtained from Fermentas; Thermo Fisher Scientific, Inc. (Waltham, MA, USA).

Animal treatment and grouping. Healthy male Sprague-Dawley rats (weight, 220-300 g; age, 8-10 weeks; n=32) were purchased from Changzhou Cavens Laboratory Animal Co., Ltd. (Changzhou, China), housed at $23-24^{\circ} \mathrm{C}, 50-60 \%$ humidity, light/dark cycle (7:00-19:00) with free access to food and water, and randomly divided into control, UC model, and treatment with 50 or $100 \mathrm{mg} / \mathrm{kg}$ D-limonene groups ( $\mathrm{n}=8 /$ group). The control group rats were subjected to enema and oral gavage with normal saline. The UC model was established by administration of $2 \%$ DSS for 7 days. For the D-limonene-treated groups, UC model rats were administered with 50 or $100 \mathrm{mg} / \mathrm{kg}$ D-limonene by gastric lavage for 7 days (17). After treatment with D-limonene, rats were sacrificed using decapitation under anesthesia (2\% pentobarbital sodium; Sigma-Aldrich; Merck KGaA).

Disease Activity Index (DAI) and Colonic Mucosa Damage Index (CMDI) scoring. Body weight, stool consistency, behavior and fecal blood in the stools of the rats were recorded daily. The scores were assigned as follows: Body weight reduction $(0$, no alteration; $1,1-5 \% ; 2,6-10 \% ; 3,11-15 \%$; $4,>15 \%$ ); stool consistency ( 0 , typical; 2 , loose; 4 , diarrhea); and the presence of fecal blood (0, typical; 2 , positive occult blood test; 4, visible bleeding). The DAI was calculated as the sum of these scores. The entire colon was excised from the cecum of rats, and macroscopic damage was evaluated using the CMDI scoring system (18), with slight modifications: 0, No inflammation; 1, local hyperemia without ulcers, and/or stool consistency; 2, ulceration without hyperemia; 3 , ulceration and adhesions at one site; 4, two or more sites of inflammation and ulceration extending $>1 \mathrm{~cm} ; 5$, ulceration $>2 \mathrm{~cm}$.

Inflammatory cytokine, antioxidant and PGE2 production. Serum was obtained from a peripheral vessel and centrifuged at $1,200 \times \mathrm{g}$ for $10 \mathrm{~min}$ at room temperature. Serum protein expression levels of TNF- $\alpha$, IL- $1 \beta$, IL- 6, NF- $\kappa$ B, SOD, GSH and PGE2 were measured using ELISA kits, and the absorbance was measured at a wavelength of $450 \mathrm{~nm}$ using an ELISA reader.

Matrix metalloproteinase (MMP)-2, -9 and transforming growth factor- $\beta$ (TGF- $\beta$ ) gene expression. Total RNA was extracted from colonic mucosa tissue samples using TRIzol ${ }^{\circledR}$ reagent (Invitrogen; Thermo Fisher Scientific, Inc.) according to the manufacturer's protocol. Equal quantities of total RNA were used to synthesize cDNA using an RNA Polymerase Chain Reaction (PCR) kit (Avian Myeoblastosis Virus 3.0; Takara Biotechnology Co., Ltd., Dalian, China), according to the manufacturer's protocol. Following this, quantitative PCR (qPCR) was performed using a SYBR ${ }^{\circledR}$-Green JumpStart ${ }^{\mathrm{TM}}$ Taq ReadyMix $^{\mathrm{TM}}$ (Sigma-Aldrich; Merck KGaA), SYBR ${ }^{\circledR}$-Green PCR Master mix (Applied Biosystems; Thermo Fisher Scientific, Inc.) and iCycler IQ ${ }^{\mathrm{TM}}$ Real-Time PCR Detection system (Bio-Rad Laboratories, Inc., Hercules, CA, USA). The sequences for gene-specific primers are presented in Table I. The thermocycling conditions for MMP-2 were as follows: Predenaturation at $95^{\circ} \mathrm{C}$ for $10 \mathrm{~min}$, followed by 35 cycles of denaturation for $30 \mathrm{sec}$ at $94^{\circ} \mathrm{C}$, annealing at $59^{\circ} \mathrm{C}$ for $30 \mathrm{sec}$ and extension at $72^{\circ} \mathrm{C}$ for $90 \mathrm{sec}$. The thermocycling conditions for MMP-9 were as follows: Predenaturation at $94^{\circ} \mathrm{C}$ for $10 \mathrm{~min}$, followed by 35 cycles of denaturation at $94^{\circ} \mathrm{C}$ for $45 \mathrm{sec}$, annealing at $62^{\circ} \mathrm{C}$ for $30 \mathrm{sec}$ and extension at $72^{\circ} \mathrm{C}$ for $90 \mathrm{sec}$. The thermocycling conditions for MMP-2, MMP-9 and TGF- $\beta$ were as follows: Predenaturation at $94^{\circ} \mathrm{C}$ for $10 \mathrm{~min}$, followed by 35 cycles of denaturation at $94^{\circ} \mathrm{C}$ for $45 \mathrm{sec}$, annealing at $58^{\circ} \mathrm{C}$ for $30 \mathrm{sec}$ and extension at $72^{\circ} \mathrm{C}$ for $90 \mathrm{sec}$. Relative quantitation values were calculated using the $2^{-\Delta \Delta \mathrm{Cq}}$ method (19).

Western blot analysis of inducible nitric oxide synthase (iNOS), cyclooxygenase (COX)-2 and extracellular signal-regulated kinase (ERK) 1/2. For western blot analysis, colonic mucosa tissue samples were obtained and homogenized with radioimmunoprecipitation assay buffer (EMD Millipore, Billerica, MA, USA). The homogenate was centrifuged at $1200 \mathrm{x} g$ for $10 \mathrm{~min}$ at $4^{\circ} \mathrm{C}$ and protein concentrations were measured using a BCA assay kit. A total of $50 \mathrm{mg}$ protein underwent $10 \%$ SDS-PAGE and was subsequently transferred onto nitrocellulose membranes (Merck KGaA). The membranes were blocked with $5 \%(\mathrm{w} / \mathrm{v})$ non-fat milk powder in Tris-buffered saline containing $0.1 \%$ Tween-20 (TBST), followed by incubation at $4^{\circ} \mathrm{C}$ overnight with the appropriate primary antibody at the following dilutions: Anti-iNOS (sc-649; 1:2,000; Santa Cruz Biotechnology, Inc., Dallas, TX, USA), anti-COX-2 (sc-7951; 1:1,000; Santa Cruz Biotechnology, Inc.) and anti-phosphorylated (p)-ERK1/2 (sc-101760; 1:2,000, Santa Cruz Biotechnology, Inc.), with anti- $\beta$-actin (D110007; 1:5,000; Sangon Biotech, Co., Ltd., Shanghai, China) serving as the internal control. Following this, membranes were washed three times in TBST for $1 \mathrm{~h}$ and incubated with horseradish peroxidase (HPR)-conjugated anti-rabbit IgG secondary antibodies for $2 \mathrm{~h}$ at room temperature (sc-2004; 1:5,000; Santa Cruz Biotechnology, Inc.). Proteins were detected using a SuperSignal ${ }^{\mathrm{TM}}$ West Femto Chemiluminescent Substrate (Thermo Fisher Scientific, Inc.) and calculated using Image-Pro Plus software version 3.0 (Media Cybernetics, Inc., Silver Spring, MD, USA). 
Table I. Primers used in the present study.

\begin{tabular}{llc}
\hline Gene & \multicolumn{1}{c}{ Sequence (5'-3') } & $\begin{array}{r}\text { Product } \\
\text { size (bp) }\end{array}$ \\
\hline MMP-2 & $\begin{array}{l}\text { F: ACCATCGCCCATCATCAAGT } \\
\text { R: CGAGCAAAAGCATCATCCAC }\end{array}$ & 348 \\
MMP-9 & F: CCCTGCGTATTTCCATTCAT & 600 \\
& R: ACCCCACTTCTTGTCAGCGTC & \\
TGF- $\beta$ & F: TGCTTCAGCTCCACAGAGAA & 284 \\
& R: TGGTTGTAGAGGGCAAGGAC & \\
$\beta$-actin & F: AAGCCTAAGGCCAACCGTGAA & 241 \\
& AAG & \\
& R: TCAATGAGGTAGTCTGTCAGGT & \\
\hline
\end{tabular}

MMP, matrix metalloproteinase; TGF, transforming growth factor- $\beta$; $\mathrm{F}$, forward; $\mathrm{R}$, reverse.

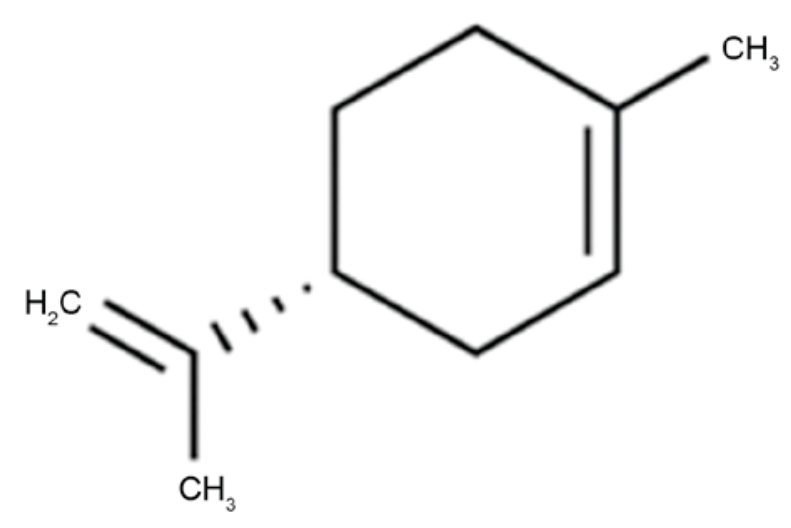

Figure 1. The chemical structure of D-limonene.

Statistical analysis. Data were analyzed by one-way analysis of variance, followed by Student-Newman-Keuls post hoc test, using SPSS version 22.0 (IBM SPSS, Armonk, NY, USA). Data are expressed as the mean \pm standard deviation. $\mathrm{P}<0.05$ was considered to indicate a statistically significant difference.

\section{Results}

DAI and CMDI scores. In the UC model group, DAI (Fig. 2A) and CMDI (Fig. 2B) scores were significantly increased compared with the control group $(\mathrm{P}=0.0011$ and 0.0000$)$. Treatment with 50 or $100 \mathrm{mg} / \mathrm{kg}$ D-limonene significantly decreased these scores compared with untreated UC rats $(\mathrm{P}=0.0039$ and $0.0021 ; \mathrm{P}=0.0044$ and 0.0015$)$.

Inflammatory cytokines. Expression levels of the inflammatory cytokines NF-אB (Fig.3A), TNF- $\alpha$ (Fig.3B), IL-1 $\beta$ (Fig. 3C) and IL-6(Fig. 3D) were significantly increased in UC rats, compared with the control group ( $\mathrm{P}=0.0017,0.0006,0.0024$ and 0.0035$)$, whereas treatment with 50 or $100 \mathrm{mg} / \mathrm{kg}$ D-limonene significantly reduced the expression levels compared with untreated $\mathrm{UC}$ rats $(\mathrm{P}=0.0079$ and $0.0051 ; \mathrm{P}=0.0066$ and 0.0049 ; $\mathrm{P}=0.0091$ and $0.0063 ; \mathrm{P}=0.0082$ and 0.0059 ).
MMP-2 and -9 gene expression. mRNA expression levels of MMP-2 (Fig. 4A) and -9 (Fig. 4B) in the colonic mucosa of $\mathrm{UC}$ rats were markedly increased, compared with the control group ( $\mathrm{P}=0.0007$ and 0.0000$)$. By contrast, MMP-2 and -9 mRNA expression levels were markedly reduced by treatment with 50 or $100 \mathrm{mg} / \mathrm{kg}$ D-limonene compared with untreated $\mathrm{UC}$ rats $(\mathrm{P}=0.0071$ and $0.0042 ; \mathrm{P}=0.00097$ and 0.0031$)$.

SOD and GSH activities. Activities of SOD (Fig. 5A) and GSH (Fig. 5B) in UC rats were reduced compared with control rats $(\mathrm{P}=0.0031$ and 0.0023$)$. Treatment with 50 or $100 \mathrm{mg} / \mathrm{kg}$ D-limonene markedly increased activities of the two antioxidants, SOD and GSH, compared with untreated UC rats ( $\mathrm{P}=0.0082$ and $0.0038 ; \mathrm{P}=0.00090$ and 0.0047 ).

iNOS protein expression levels. As presented in Fig. 6, there was a significant increase in iNOS protein expression levels in UC rats compared with the control group $(\mathrm{P}=0.0053)$. Treatment with 50 or $100 \mathrm{mg} / \mathrm{kg}$ D-limonene significantly reduced iNOS protein expression levels compared with untreated $\mathrm{UC}$ rats $(\mathrm{P}=0.0046$ and 0.0016$)$.

COX-2 protein expression levels. UC rats exhibited increased protein expression levels of COX-2 compared with control rats $(\mathrm{P}=0.0078$; Fig. 7). Treatment with 50 or $100 \mathrm{mg} / \mathrm{kg}$ D-limonene significantly decreased COX-2 protein expression levels compared with untreated UC rats $(\mathrm{P}=0.0062$ and 0.0029$)$.

PGE2 production. The effect of D-limonene on $\mathrm{PGE} 2$ production was assessed in UC rats. There was a significant increase in PGE2 production in UC rats compared with the control group ( $\mathrm{P}=0.0012$; Fig. 8). Treatment with 50 or $100 \mathrm{mg} / \mathrm{kg}$ D-limonene significantly reduced PGE2 production compared with untreated UC rats $(\mathrm{P}=0.0071$ and 0.0033$)$.

TGF- $\beta$ gene expression. The effect of D-limonene on TGF- $\beta$ gene expression in UC rats is presented in Fig. 9. TGF- $\beta$ mRNA expression levels were significantly increased in UC rats compared with the control group $(\mathrm{P}=0.0039)$. However, treatment with 50 or $100 \mathrm{mg} / \mathrm{kg}$ D-limonene significantly reduced TGF- $\beta$ mRNA expression levels compared with untreated $\mathrm{UC}$ rats $(\mathrm{P}=0.0052$ and 0.0016$)$.

p-ERK1/2 protein expression levels. To assess the effects of D-limonene on the ERK1/2 signaling pathway, p-ERK1/2 protein expression levels were measured. Western blot analysis revealed that $\mathrm{p}$-ERK1/2 protein expression levels were significantly reduced in $\mathrm{UC}$ rats compared with control rats $(\mathrm{P}=0.0058$; Fig. 10). However, treatment with 50 or $100 \mathrm{mg} / \mathrm{kg}$ D-limonene significantly increased p-ERK1/2 protein expression levels compared with untreated UC rats $(\mathrm{P}=0.0028$ and 0.0006$)$.

\section{Discussion}

$\mathrm{UC}$ is a type of inflammatory bowel disease. It is hypothesized that the pathogenesis of UC involves the activation of the immune system by various microbial antigens, based on genetic material and environmental factors. This results in an imbalance of cytokines, which activates a variety of inflammatory cells and recruits these cells to the site of 
A

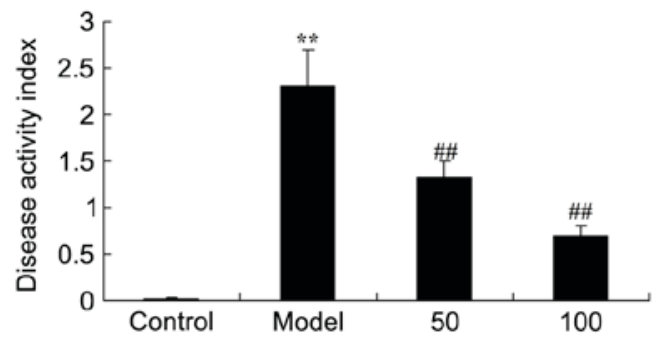

B

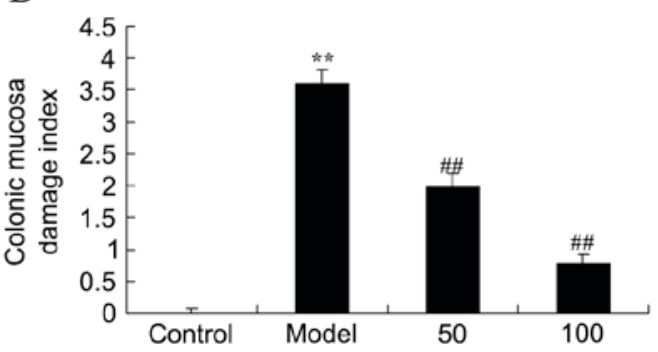

Figure 2. Disease activity index and colonic mucosa damage index scores. Quantification of (A) disease activity index and (B) colonic mucosa damage in ulcerative colitis rats, following treatment with 50 or $100 \mathrm{mg} / \mathrm{kg} \mathrm{D}$-limonene. Data are presented as the mean \pm standard deviation. ${ }^{* *} \mathrm{P}<0.05 \mathrm{vs}$. control group; ${ }^{\# \#} \mathrm{P}<0.05$ vs. model group. Control, control group; model, ulcerative colitis model; $50,50 \mathrm{mg} / \mathrm{kg}$ D-limonene treated group; $100,100 \mathrm{mg} / \mathrm{kg} \mathrm{D}-\mathrm{imonene}$ treated group.

A

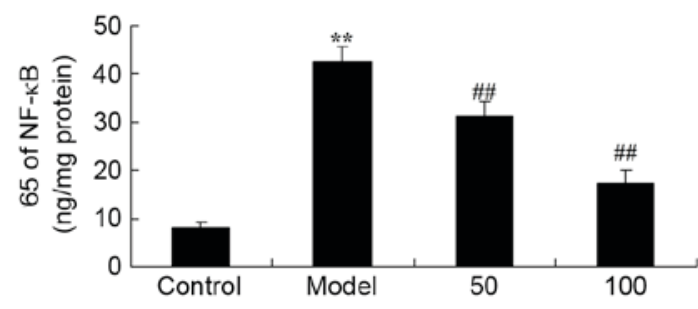

$\mathrm{C}$

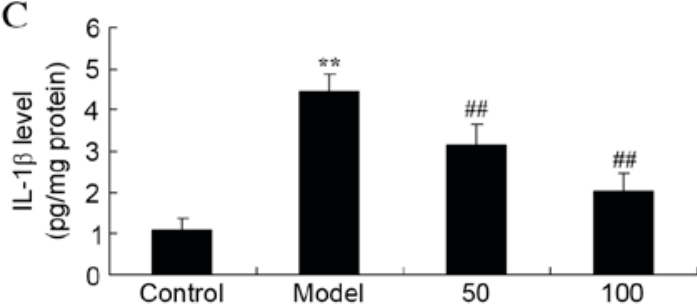

B

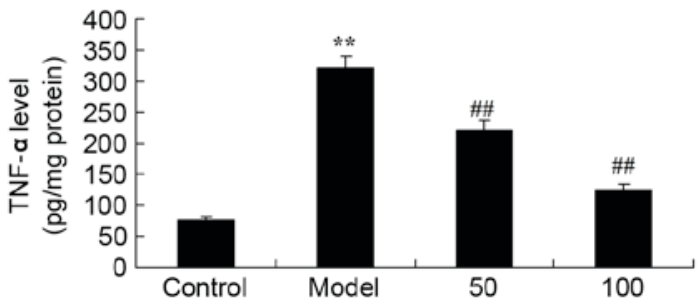

$\mathrm{D}$

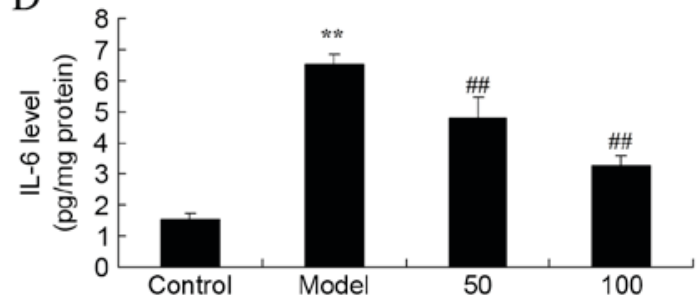

Figure 3. Inflammatory cytokines. Protein expression levels of (A) NF- $\kappa$ B p65 subunit, (B) TNF- $\alpha$, (C) IL-1 $\beta$ and (D) IL-6 in ulcerative colitis rats, following treatment with 50 or $100 \mathrm{mg} / \mathrm{kg}$ D-limonene. Control, control group; model, ulcerative colitis model; 50, $50 \mathrm{mg} / \mathrm{kg} \mathrm{D}-\mathrm{limonene} \mathrm{treated} \mathrm{group;} \mathrm{100,} \mathrm{100} \mathrm{mg/kg}$ D-limonene treated group. Data are presented as the mean \pm standard deviation. ${ }^{* *} \mathrm{P}<0.05$ vs. control group; ${ }^{\# \#} \mathrm{P}<0.05$ vs. model group. IL, interleukin; TNF- $\alpha$, transforming growth factor- $\alpha$; NF- $\kappa \mathrm{B}$, nuclear factor $\kappa \mathrm{B}$.

A

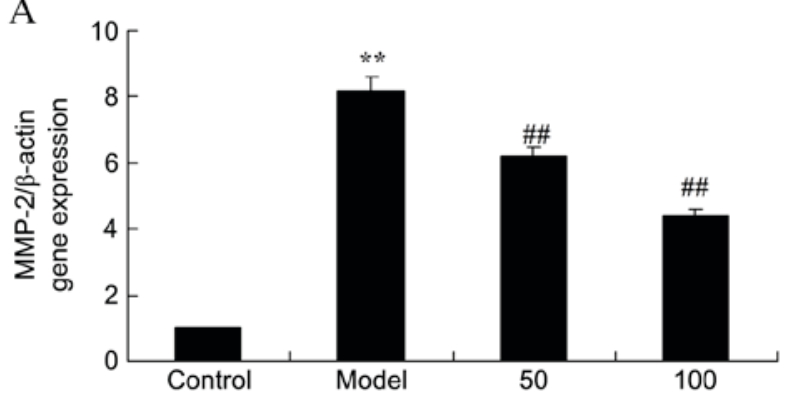

B

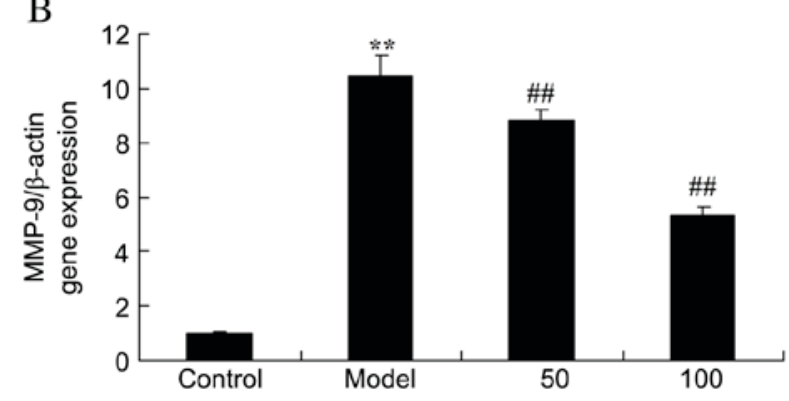

Figure 4. MMP-2 and MMP-9 gene expression. Quantification of (A) MMP-2 and (B) MMP-9 mRNA expression levels in ulcerative colitis rats, following treatment with 50 or $100 \mathrm{mg} / \mathrm{kg}$ D-limonene. Data are presented as the mean \pm standard deviation. ${ }^{* *} \mathrm{P}<0.05 \mathrm{vs}$. control group; ${ }^{\# \#} \mathrm{P}<0.05 \mathrm{vs}$. model group. MMP, matrix metalloproteinase; Control, control group; model, ulcerative colitis model; 50, $50 \mathrm{mg} / \mathrm{kg}$ D-limonene treated group; $100,100 \mathrm{mg} / \mathrm{kg}$ D-limonene treated group.

inflammation, releasing further inflammatory cytokines and thus leading to chronic inflammation of the colon $(20,21)$. The present study demonstrated that treatment with D-limonene significantly suppressed the DAI and CMDI, and inhibited TNF- $\alpha$, IL-1 $\beta$, IL- 6 and NF- $\kappa B$ expression levels, in UC rats. Hirota et al (22) identified that D-limonene reduces allergic airway inflammation via inhibition of the expression levels of IL-5, IL-13, eotaxin, monocyte chemoattractant protein-1 and TGF- $\beta 1$ in Dermatophagoides farinae-treated mice. Therefore, D-limonene may be a novel therapeutic agent for the treatment of UC.

During the process of oxidation, a variety of highly chemically reactive oxygen species may be generated, which leads to intestinal tissue damage and ulceration. The oxygen free 
A

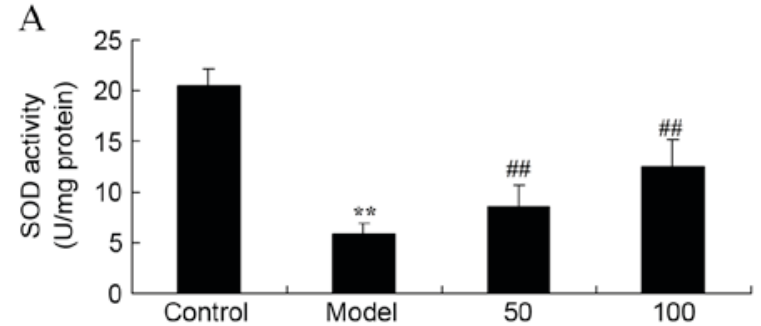

$\mathrm{B}$

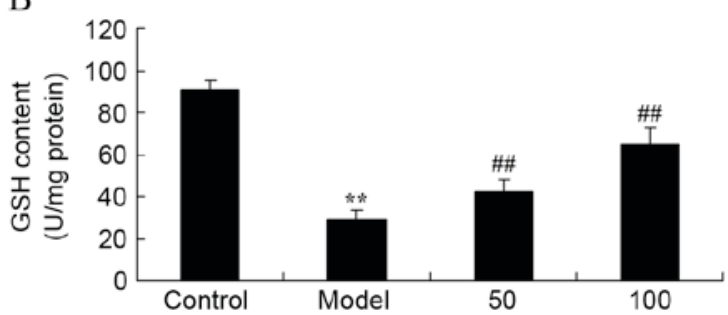

Figure 5. Antioxidant activity. Quantification of (A) SOD and (B) GSH activities in ulcerative colitis rats, following treatment with 50 or $100 \mathrm{mg} / \mathrm{kg}$ D-limonene. Data are presented as the mean \pm standard deviation. ${ }^{* *} \mathrm{P}<0.05$ vs. control group; ${ }^{\# \#} \mathrm{P}<0.05$ vs. model group. SOD, superoxide dismutase; GSH, glutathione; Control, control group; model, ulcerative colitis model; 50,50 mg/kg D-limonene treated group; 100, $100 \mathrm{mg} / \mathrm{kg}$ D-limonene treated group.

A

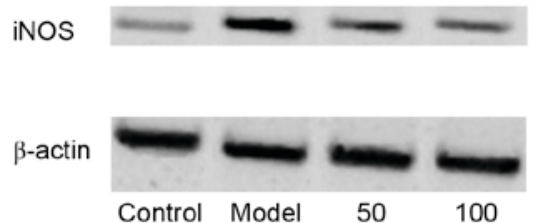

B

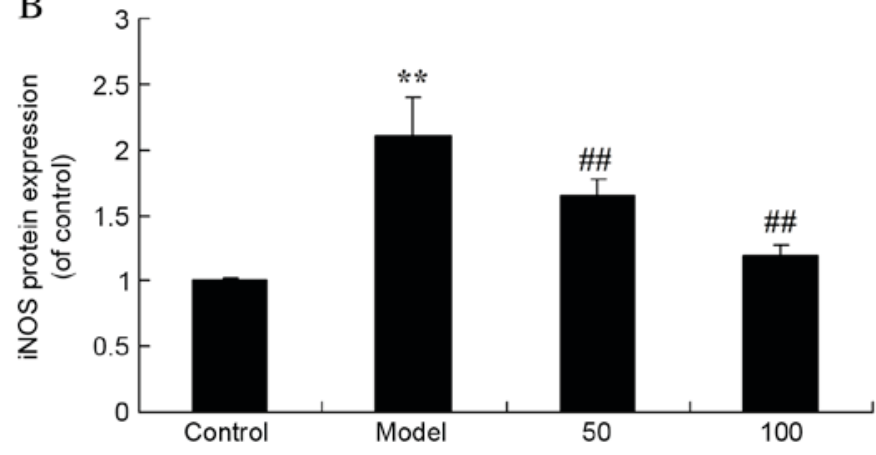

Figure 6. iNOS protein expression levels. (A) Representative western blot images and (B) quantification of iNOS protein expression levels in ulcerative colitis rats, following treatment with 50 or $100 \mathrm{mg} / \mathrm{kg} \mathrm{D}$-limonene. $\beta$-actin served as an internal control. Data are presented as the mean \pm standard deviation. ${ }^{* *} \mathrm{P}<0.05$ vs. control group; ${ }^{\# \#} \mathrm{P}<0.05$ vs. model group. iNOS, inducible nitric oxide synthase; Control, control group; model, ulcerative colitis model; $50,50 \mathrm{mg} / \mathrm{kg}$ D-limonene treated group; 100, $100 \mathrm{mg} / \mathrm{kg}$ D-limonene treated group.

A

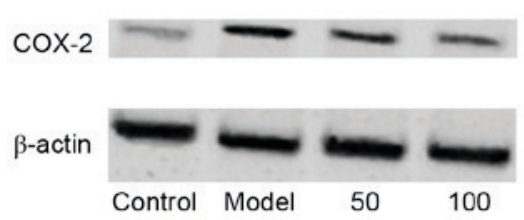

B

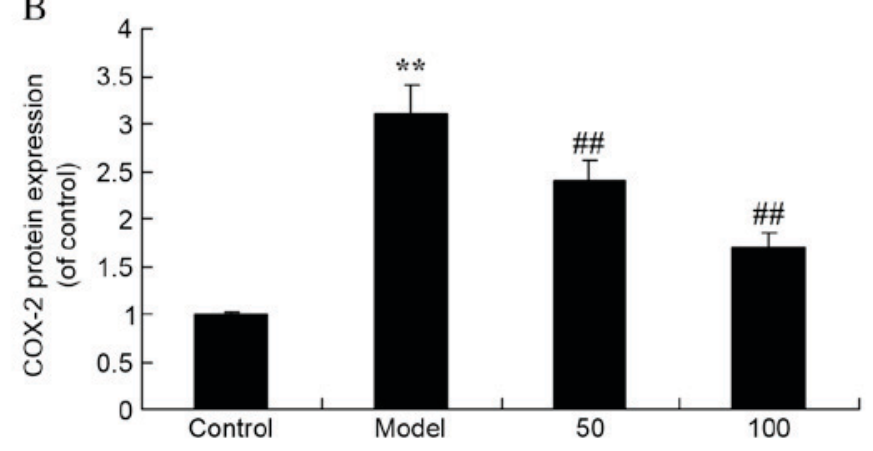

Figure 7. COX-2 protein expression levels. (A) Representative western blot images and (B) quantification of COX-2 protein expression levels in ulcerative colitis rats, following treatment with 50 or $100 \mathrm{mg} / \mathrm{kg}$ D-limonene. $\beta$-actin served as an internal control. Data are presented as the mean \pm standard deviation. ${ }^{* *} \mathrm{P}<0.05$ vs. control group; ${ }^{\# \#} \mathrm{P}<0.05$ vs. model group. COX-2, cyclooxygenase 2; Control, control group; model, ulcerative colitis model; $50,50 \mathrm{mg} / \mathrm{kg}$ D-limonene treated group; $100,100 \mathrm{mg} / \mathrm{kg}$ D-limonene treated group.

radical scavenging capacity of UC patients is decreased, therefore exacerbating disease (23). SOD is an important enzyme involved in the scavenging of oxygen free radicals and therefore preventing tissue damage; however, excessive levels of nitrous oxide reduces SOD levels, thus reducing its ability to scavenge oxygen free radicals $(24,25)$. A build-up of free radicals induces a series of chain reactions, leading to biofilm lipid peroxidation, and thus continuously disrupts the normal structure and function of the enzyme (26). The present study demonstrated that D-limonene treatment markedly increased SOD and GSH activities in UC rats. Furthermore, Rizk et al (27) reported that D-limonene suppressed SOD and
GSH activities in Schistosoma mansoni-infected mice. Thus, D-limonene may have antioxidative effects in UC rats.

COX-2 is expressed at low levels in healthy mucosa and during UC remission; however, its expression levels are significantly increased in active UC. It is primarily expressed in epithelial, endothelial and inflammatory cells (28). The enhanced expression levels of COX-2 are a protective response in the recovery process, which improves the protection of intestinal mucosal cells, promotes the hyperplasia of intestinal epithelial cells and intestinal blood flow, and promotes the repair of epithelial cells. COX-2 may inhibit the apoptosis of epithelial cells by reducing arachidonic acid (AA) and regulating 


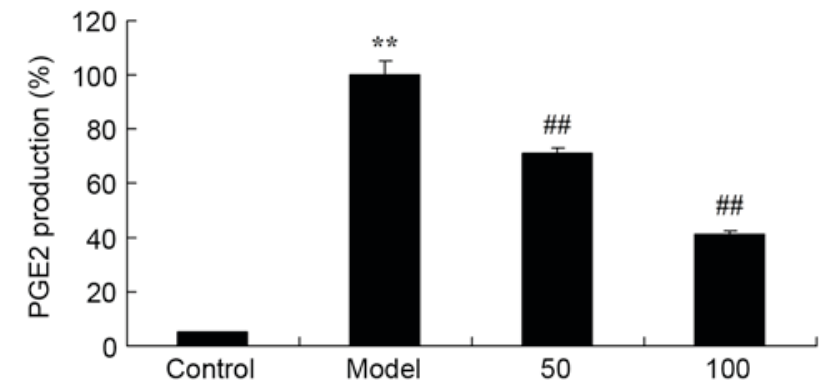

Figure 8. PGE2 production. Quantification of PGE2 protein expression levels in ulcerative colitis rats, following treatment with 50 or $100 \mathrm{mg} / \mathrm{kg}$ D-limonene. Data are presented as the mean \pm standard deviation. ${ }^{* *} \mathrm{P}<0.05$ vs. control group; ${ }^{\# \#} \mathrm{P}<0.05$ vs. model group. PGE2, prostaglandin E2; Control, control group; model, ulcerative colitis model; $50,50 \mathrm{mg} / \mathrm{kg}$ D-limonene treated group; $100,100 \mathrm{mg} / \mathrm{kg}$ D-limonene treated group.

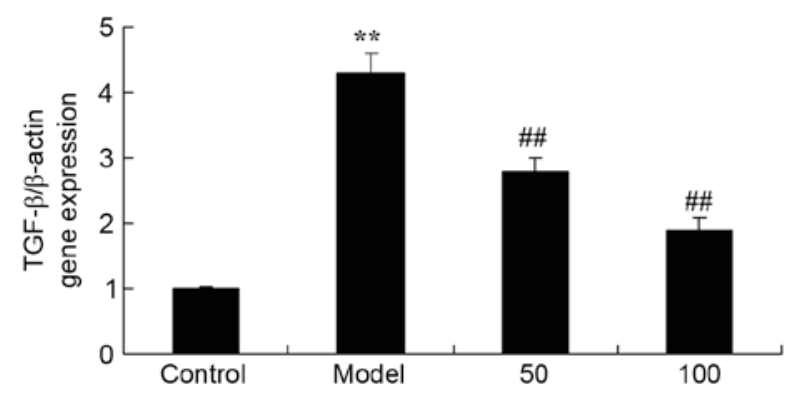

Figure 9. TGF- $\beta$ gene expression. Quantification of TGF- $\beta$ mRNA expression levels in ulcerative colitis rats, following treatment with 50 or $100 \mathrm{mg} / \mathrm{kg}$ D-limonene. Data are presented as the mean \pm standard deviation. ${ }^{* *} \mathrm{P}<0.05$ vs. control group; ${ }^{\#} \mathrm{P}<0.05$ vs. model group. Control, control group; model, ulcerative colitis model; $50,50 \mathrm{mg} / \mathrm{kg}$ D-limonene treated group; $100,100 \mathrm{mg} / \mathrm{kg}$ D-limonene treated group; TGF- $\beta$, transforming growth factor- $\beta$.

B-cell lymphoma 2, and is additionally a key enzyme for the synthesis of PGs (29). The membrane phospholipids release AA products, and produce a variety of PGs and leukotrienes by COX (30). These inflammatory mediators cause symptoms including redness, swelling, heat, pain, edema and inflammatory cell infiltration, which may affect bowel transport, bowel activity and immune regulation, thus aggravating the existing inflammation (29). The present study demonstrated that D-limonene treatment significantly reduced MMP-2 and -9mRNA expression levels, and iNOS and COX-2 protein expression levels, in UC rats. Wilson et al (13) identified that D-limonene may suppress MMP-2 and -9. Rehman et al (15) demonstrated that D-limonene inhibits doxorubicin-induced oxidative stress and inflammation via COX-2 and iNOS signaling pathways in the kidneys of Wistar rats.

PGE2, a type of PG, is a metabolite of the 20-carbon unsaturated fatty acid AA (31). AA exists in the cell membrane phospholipid bilayer, and upon exposure to external stimuli, is hydrolyzed by activated phospholipase A2 and C, and is synthesized to PG. This process is mediated by COX and a series of synthetases (31). PGE2 is an important inflammatory factor and a previous study (32) demonstrated that it may increase vascular permeability and cause edema, inducing leukocytechemotaxis, leading to inflammatory cell infiltration, and thus resulting in colonic mucosal inflammation, tissue damage and ulceration. An additional study (33) demonstrated
A
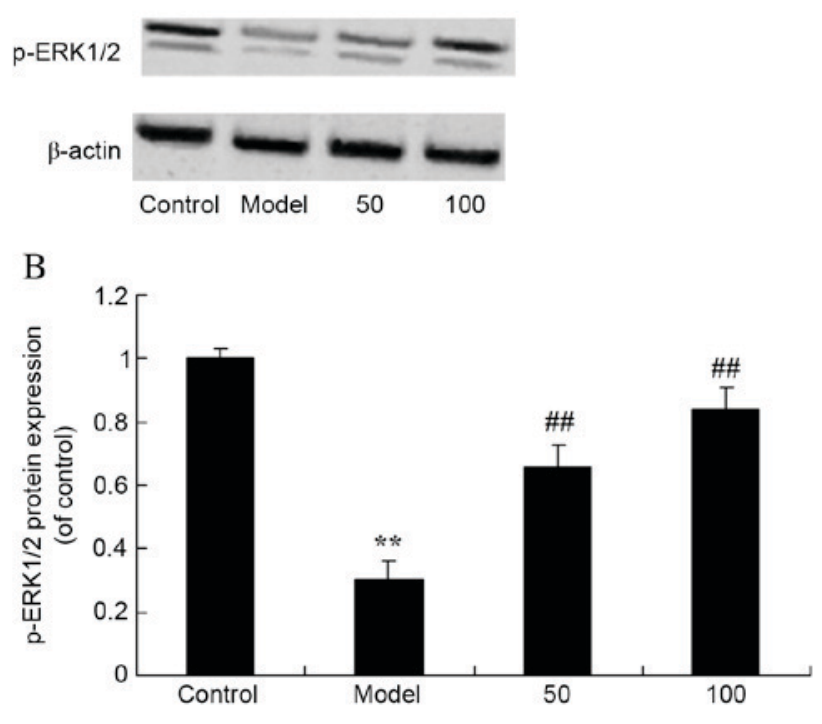

Figure 10. p-ERK1/2 protein expression levels. (A) Representative western blot images and (B) quantification of p-ERK1/2 protein expression levels in ulcerative colitis rats, following treatment with 50 or $100 \mathrm{mg} / \mathrm{kg}$ D-limonene. $\beta$-actin served as an internal control. Data are presented as the mean \pm standard deviation. ${ }^{* *} \mathrm{P}<0.05$ vs. control group; ${ }^{\# \#} \mathrm{P}<0.05$ vs. model group. Control, control group; model, ulcerative colitis model; $50,50 \mathrm{mg} / \mathrm{kg}$ D-limonene treated group; 100, $100 \mathrm{mg} / \mathrm{kg}$ D-limonene treated group; ERK 1/2, extracellular signal regulated kinase; $\mathrm{p}$, phosphorylated.

that mucosal PGE2 content in UC patients is significantly increased, and is associated with the degree of mucosal inflammation. The present study revealed that treatment with D-limonene significantly decreased PGE2 production in $\mathrm{UC}$ rats. Yoon et al (16) suggested that D-limonene reduces lipopolysaccharide-induced production of iNOS and PGE2 in RAW 334.7 macrophages.

TGF- $\beta$ is a cytokine with a variety of physiological functions. Mothers against decapentaplegic (SMAD) proteins are signaling molecules within cells that may be activated by the compound generated by TGF- $\beta$ and its receptor, which additionally transmits the signals into the nucleus (34). The TGF- $\beta 1 /$ SMAD3 signaling pathway contributes to the regulation of the immune response, induces the synthesis of the extracellular matrix components, collagen and mucin, inhibits the release of extracellular collagen proteolytic enzymes, promotes fibrosis, and facilitates repair of damaged tissue. A previous study (35) demonstrated that compared with healthy individuals, the expression levels of TGF- $\beta 1$ and $-\beta 2$ protein and mRNA in active or non-active UC patients were significantly increased. In the present study, D-limonene significantly inhibited TGF- $\beta$ mRNA expression levels in UC rats.

ERK is an important member of the mitogen-activated protein kinase (MAPK) system, which serves important roles in the mediation of inflammatory responses and the regulation of inflammatory cytokine production, the promotion of epithelial cell proliferation and differentiation, and the inhibition of intestinal epithelium apoptosis (36). p-ERK1/2 translocates from the cytoplasm to the nucleus and is thus involved in a variety of cellular biological reactions (37). 
The MAPK signaling pathway is important for the biological effect of TGF- $\beta 1(38,39)$. It has been reported $(38)$ that the relative protein expression levels of $\mathrm{p}-\mathrm{ERK} 1 / 2$ and $\mathrm{p}-\mathrm{MAPK}$ kinase $1 / 2$ in the colonic mucosa of UC rats are increased compared with healthy rats. Rufino et al (40) demonstrated that D-limonene may have anti-inflammatory, anticatabolic and proanabolic effects in a cell model of osteoarthritis via increasing ERK1/2 activation. The results of the present study revealed that D-limonene significantly activated the ERK1/2 signaling pathway in UC rats.

In conclusion, the present study demonstrated the that D-limonene suppresses MMP-2 and -9 mRNA expression levels via regulation of the iNOS, COX-2, PGE2, TGF- $\beta$ and ERK1/2 signaling pathways in a UC rat model, indicating its potential antioxidant and anti-inflammatory properties. The current study indicates that D-limonene may be a novel potential target for the therapeutic effects of UC.

\section{References}

1. Brandse JF, van den Brink GR, Wildenberg ME, van der Kleij D, Rispens T, Jansen JM, Mathôt RA, Ponsioen CY, Löwenberg M and D'Haens GR: Loss of infliximab into feces is associated with lack of response to therapy in patients with severe ulcerative colitis. Gastroenterology 149: 350-355.e2, 2015.

2. Boschetti G, Nancey S, Moussata D, Stefanescu C, Roblin X, Chauvenet M, Stroeymeyt K, Bouhnik Y and Flourié B: Tacrolimus induction followed by maintenance monotherapy is useful in selected patients with moderate-to-severe ulcerative colitis refractory to prior treatment. Dig Liver Dis 46: 875-880, 2014.

3. Okuyama Y, Andoh A, Nishishita M,Fukunaga K, Kamikozuru K, Yokoyama Y, Ueno Y, Tanaka S, Kuge H, Yoshikawa S, et al: Multicenter prospective study for clinical and endoscopic efficacies of leukocytapheresis therapy in patients with ulcerative colitis. Scand J Gastroenterol 48: 412-418, 2013.

4. Cleynen I, Boucher G, Jostins L, Schumm LP, Zeissig S, Ahmad T, Andersen V, Andrews JM, Annese V, Brand S, et al: Inherited determinants of Crohn's disease and ulcerative colitis phenotypes: A genetic association study. Lancet 387: 156-167, 2016.

5. Heikens JT, de Vries J, de Jong DJ, den Oudsten BL, Hopman W, Groenewoud JM, van der Kolk MB, Gooszen HG and van Laarhoven CJ: Evaluation of long-term function, complications, quality of life and health status after restorative proctocolectomy with ileo neo rectal and with ileal pouch anal anastomosis for ulcerative colitis. Colorectal Dis 15: e323-e329, 2013.

6. Adedokun OJ, Xu Z, Padgett L, Blank M, Johanns J, Griffiths A, Ford J, Zhou H, Guzzo C, Davis HM and Hyams J: Pharmacokinetics of infliximab in children with moderate-to-severe ulcerative colitis: Results from a randomized, multicenter, open-label, phase 3 study. Inflamm Bowel Dis 19: 2753-2762, 2013.

7. Guardiola J, Lobatón T, Rodríguez-Alonso L, Ruiz-Cerulla A Arajol C, Loayza C, Sanjuan X, Sánchez E and Rodríguez-Moranta F: Fecal level of calprotectin identifies histologic inflammation in patients with ulcerative colitis in clinical and endoscopic remission. Clin Gastroenterol Hepatol 12: 1865-1870, 2014

8. Takeda Y, Nakase H, Namba K, Inoue S, Ueno S, Uza N and Chiba T: Upregulation of T-bet and tight junction molecules by Bifidobactrium longum improves colonic inflammation of ulcerative colitis. Inflamm Bowel Dis 15: 1617-1618, 2009.

9. Laake KO, Line PD, Aabakken L, Løtveit T, Bakka A, Eide J, Roseth A, Grzyb K, Bjørneklett A and Vatn MH: Assessment of mucosal inflammation and circulation in response to probiotics in patients operated with ileal pouch anal anastomosis for ulcerative colitis. Scand J Gastroenterol 38: 409-414, 2003.

10. Yang SK, Jung HY, Kang GH, Kim YM, Myung SJ, Shim KN, Hong WS and Min YI: Appendiceal orifice inflammation as a skip lesion in ulcerative colitis: An analysis in relation to medical therapy and disease extent. Gastrointest Endosc 49: 743-747, 1999.
11. Mawdsley JE, Jenkins DG, Macey MG, Langmead L and Rampton DS: The effect of hypnosis on systemic and rectal mucosal measures of inflammation in ulcerative colitis. Am J Gastroenterol 103: 1460-1469, 2008.

12. Mannon PJ, Hornung RL, Yang Z, Yi C, Groden C, Friend J, Yao M, Strober W and Fuss IJ: Suppression of inflammation in ulcerative colitis by interferon-b-1a is accompanied by inhibition of IL-13 production. Gut 60: 449-455, 2011.

13. Wilson MJ, Lindgren BR and Sinha AA: The effect of dietary supplementation with limonene or myo-inositol on the induction of neoplasia and matrix metalloproteinase and plasminogen activator activities in accessory sex organs of male Lobund-Wistar rats. Exp Mol Pathol 85: 83-89, 2008.

14. Marmulla R and Harder J: Microbial monoterpene transformations-a review. Front Microbiol 5: 346, 2014.

15. Rehman MU, Tahir M, Khan AQ, Khan R, Oday-O-Hamiza, Lateef A, Hassan SK, Rashid S, Ali N, Zeeshan M and Sultana S: D-limonene suppresses doxorubicin-induced oxidative stress and inflammation via repression of COX-2, iNOS, and NFKB in kidneys of Wistar rats. Exp Biol Med (Maywood) 239: 465-476, 2014.

16. Yoon WJ, Lee NH and Hyun CG: Limonene suppresses lipopolysaccharide-induced production of nitric oxide, prostaglandin E2, and pro-inflammatory cytokines in RAW 2647 macrophages. J Oleo Sci 59: 415-421, 2010.

17. Chaudhary SC, Siddiqui MS, Athar M and Alam MS: D-Limonene modulates inflammation, oxidative stress and Ras-ERK pathway to inhibit murine skin tumorigenesis. Hum Exp Toxicol 31: 798-811, 2012.

18. Mao JW, He XM, Tang HY and Wang YD: Protective role of metalloproteinase inhibitor (AE-941) on ulcerative colitis in rats. World J Gastroenterol 18: 7063-7069, 2012.

19. Livak KJ and Schmittgen TD: Analysis of relative gene expression data using real-time quantitative PCR and the 2(-Delta Delta C(T)) Method. Methods 25: 402-408, 2001

20. Van Assche G, Manguso F, Zibellini M, Cabriada Nuño JL, Goldis A, Tkachenko E, Varoli G, Kleczkowski D, Annese V, D'Heygere F, et al: Oral prolonged release beclomethasone dipropionate and prednisone in the treatment of active ulcerative colitis: Results from a double-blind, randomized, parallel group study. Am J Gastroenterol 110: 708-715, 2015.

21. Trifan A, Stanciu C, Stoica O, Girleanu I and Cojocariu C: Impact of Clostridium difficile infection on inflammatory bowel disease outcome: A review. World J Gastroenterol 20: 11736-11742, 2014.

22. Hirota R, Nakamura H, Bhatti SA, Ngatu NR, Muzembo BA, Dumavibhat N, Eitoku M, Sawamura M and Suganuma N: Limonene inhalation reduces allergic airway inflammation in Dermatophagoides farinae-treated mice. Inhal Toxicol 24: 373-381, 2012.

23. Jorgensen JR and Mortensen PB: Influence of feces from patients with ulcerative colitis on butyrate oxidation in rat colonocytes. Dig Dis Sci 44: 2099-2109, 1999.

24. Alagozlu H, Gorgul A, Bilgihan A, Tuncer C and Unal S: Increased plasma levels of advanced oxidation protein products (AOPP) as a marker for oxidative stress in patients with active ulcerative colitis. Clin Res Hepatol Gastroenterol 37: 80-85, 2013.

25. Keshavarzian A, Banan A, Farhadi A, Komanduri S, Mutlu E, Zhang Y and Fields JZ: Increases in free radicals and cytoskeletal protein oxidation and nitration in the colon of patients with inflammatory bowel disease. Gut 52: 720-728, 2003.

26. Roediger WE: Review article: Nitric oxide from dysbiotic bacterial respiration of nitrate in the pathogenesis and as a target for therapy of ulcerative colitis. Aliment Pharmacol Ther 27: 531-541, 2008.

27. Rizk M, Ibrahim N and El-Rigal N: Comparative in vivo antioxidant levels in Schistosoma mansoni infected mice treated with praziquantel or the essential oil of Melaleuca armillaris leaves. Pak J Biol Sci 15: 971-978, 2012.

28. Zhang CX, Guo LK and Guo XF: Interaction between the polymorphisms of cyclooxygenase-2-1195G/A, MnSOD9Ala/val genes and the high-fat diets and its correlation with ulcerative colitis. Zhongguo Yi Xue Ke Xue Yuan Xue Bao 37: 37-43, 2015.

29. Abdallah Hajj Hussein I, Freund JN, Reimund JM, Shams A, Yamine M, Leone A and Jurjus AR: Enteropathogenic e.coli sustains iodoacetamide-induced ulcerative colitis-like colitis in rats: Modulation of IL-1 $\beta$, IL-6, TNF- $\alpha$, COX-2, and apoptosisi. J Biol Regul Homeost Agents 26: 515-526, 2012. 
30. Fratila OC and Ilias TI: COX-2 and Ki-67 immunohistochemical markers in the assessment of long-standing ulcerative colitis associated dysplasia. Rom J Morphol Embryol 54: 143-149, 2013.

31. Roulis M, Nikolaou C, Kotsaki E, Kaffe E, Karagianni N, Koliaraki V, Salpea K, Ragoussis J, Aidinis V, Martini E, et al: Intestinal myofibroblast-specific Tpl2-Cox-2-PGE2 pathway links innate sensing to epithelial homeostasis. Proc Natl Acad Sci USA 111: E4658-E4667, 2014.

32. Tammali R, Ramana KV and Srivastava SK: Aldose reductase regulates TNF-alpha-induced PGE2 production in human colon cancer cells. Cancer Lett 252: 299-306, 2007.

33. Guan F, Wang H, Shan Y, Chen Y, Wang M, Wang Q, Yin M, Zhao Y, Feng $X$ and Zhang J: Inhibition of COX-2 and PGE in LPS-stimulated RAW264.7 cells by lonimacranthoide VI, a chlorogenic acid ester saponin. Biomed Rep 2: 760-764, 2014.

34. Li C, Iness A, Yoon J, Grider JR, Murthy KS, Kellum JM and Kuemmerle JF: Noncanonical STAT3 activation regulates excess TGF- $\beta 1$ and collagen I expression in muscle of stricturing Crohn's disease. J Immunol 194: 3422-3431, 2015.

35. Fleissner D, Frede A, Knott M, Knuschke T, Geffers R, Hansen W, Dobos G, Langhorst J, Buer J and Westendorf AM: Generation and function of immunosuppressive human and murine CD8+ $\mathrm{T}$ cells by transforming growth factor- $\beta$ and retinoic acid. Immunology 134: 82-92, 2011.
36. Setia S, Nehru B and Sanyal SN: Upregulation of MAPK/Erk and PI3K/Akt pathways in ulcerative colitis-associated colon cancer. Biomed Pharmacother 68: 1023-1029, 2014.

37. Dambacher J, Beigel F, Seiderer J, Haller D, Göke B, Auernhammer CJ and Brand S: Interleukin 31 mediates MAP kinase and STAT1/3 activation in intestinal epithelial cells and its expression is upregulated in inflammatory bowel disease. Gut 56: 1257-1265, 2007.

38. Lv Q, Qiao SM, Xia Y, Shi C, Xia YF, Chou GX, Wang ZT, Dai Y and Wei ZF: Norisoboldine ameliorates DSS-induced ulcerative colitis in mice through induction of regulatory $\mathrm{T}$ cells in colons. Int Immunopharmacol 29: 787-797, 2015.

39. Rezaie A, Khalaj S, Shabihkhani M, Nikfar S, Zamani MJ, Mohammadirad A, Daryani NE and Abdollahi M: Study on the correlations among disease activity index and salivary transforming growth factor-beta 1 and nitric oxide in ulcerative colitis patients. Ann N Y Acad Sci 1095: 305-314, 2007.

40. Rufino AT, Ribeiro M, Sousa C, Judas F, Salgueiro L, Cavaleiro C and, Mendes AF: Evaluation of the anti-inflammatory, anti-catabolic and pro-anabolic effects of E-caryophyllene, myrcene and limonene in a cell model of osteoarthritis. Eur J Pharmacol 750: 141-150, 2015. 